\title{
Concepções de ciência de um grupo de licenciandas em Pedagogia e suas relações com o processo formativo
}

\author{
Science conceptions of a group of pedagogy graduation \\ students and their relation to the training process
}

\author{
Ana Lúcia Santos Souza ${ }^{1}$ • Daisi Teresinha Chapani ${ }^{2}$
}

\begin{abstract}
Resumo: Este artigo apresenta uma análise das concepções de ciência de um grupo de licenciandas de um curso de Licenciatura em Pedagogia e suas relações com as concepções apresentadas em documentos do curso e pela docente da disciplina Conteúdos e Metodologia do Ensino Fundamental de Ciências. Partimos das seguintes questões: uais as concepções de ciência demonstradas por concluintes do curso de Licenciatura em Pedagogia? Como essas concepções podem estar relacionadas ao processo formativo das licenciandas? O estudo ampara-se teoricamente em Habermas, que considera três tradições das ciências: empírico-analítica, histórico-hermenêutica e crítica. Os dados foram constituídos por meio de documentos e entrevistas semiestruturadas. Os resultados demonstraram que a abordagem crítica que fundamenta o curso não foi materializada na construção ou revisão das concepções de ciência das discentes durante seu processo formativo, prevalecendo entre as mesmas, sobretudo, concepções de cunho positivista.
\end{abstract}

Palavras-chave: Ensino Superior. Pedagogia. Formação de professores. Ensino de ciências.

\begin{abstract}
This paper presents an analysis of the conceptions of science of a group of undergraduate program of Pedagogy for teachers (Licenciatura in Pedagogy) and the relations with the concepts presented in the program documents and by the professor of the discipline 'Elementary Science Contents and Methodology'. We start with the following questions: What are the conceptions of science demonstrated by these future teachers? How can these conceptions be related to their educational process? The research has theoretical support of Habermas studies, which considers three traditions of science: empirical-analytical, historical-hermeneutic and critical. We collected the data by means of semi-structured interviews and documents. The results showed that the critical approach that underlies the program has not materialized in the construction or revision of the future teachers' conceptions of science during their formative process, and the prevailing conceptions are mainly of a positivist nature.
\end{abstract}

Keywords: Higher education. Pedagogy. Teacher training. Science teaching.

\footnotetext{
${ }^{1}$ Departamento de Filosofia e Ciências Humanas, Universidade Estadual do Sudoeste da Bahia (UESB), caixa postal 95, CEP 45031-900, Vitória da Conquista, BA, Brasil. E-mail: <ubatense@yahoo.com.br>.

${ }^{2}$ Departamento de Ciências Biológicas, Universidade Estadual do Sudoeste da Bahia (UESB), Jequié, BA, Brasil.
} 


\section{Introdução}

A formação de professores para o ensino de Ciências nos anos iniciais de escolaridade é realizada, comumente, em cursos de Licenciatura plena em Pedagogia. As pesquisas que tratam da formação docente para esta etapa de ensino (LONGHINI, 2008; OVIGLI; BERTUCCI, 2009; SCHWARTZMAN; CHRISTOPHE, 2009; WEISSMANN, 1998) denunciam os limites que se interpõem entre o perfil do professor formado e as exigências e especificidades requeridas para a abordagem de conteúdos científicos nos primeiros anos da vida escolar.

Por outro lado, Carvalho e Gil-Pérez (2003), ao descreverem as principais necessidades formativas de professores de Ciências, destacam a importância de se problematizarem as visões simplistas de ciência, de modo que sua construção seja entendida como um processo histórico, passível de erros, reformulações e contestações.

Presenciamos, nas últimas décadas, tanto em nível nacional quanto internacional, o aumento considerável de estudos sobre a natureza da ciência e suas implicações para o processo de ensino e aprendizagem (HARRES, 1999; PUJALTE et al., 2014). No entanto, a maior parte desses estudos está voltada para professores e futuros professores de Ciências, com formação específica nesse campo; trabalhos que levantam e analisam as concepções de pedagogos ou estudantes de curso de pedagogia sobre o assunto são mais raros. No contexto brasileiro, por exemplo, citamos o trabalho de Andrade (2008), que, embasado em contribuições da nova filosofia da ciência, analisou concepções de ciências de estudantes de um curso de Pedagogia, notando a presença de concepções pouco satisfatórias coexistindo com outras mais consistentes com a epistemologia contemporânea.

Por essas razões, consideramos relevante investigar as concepções de ciência de futuros professores dos anos iniciais, relacionando-as com o processo formativo desenvolvido no curso de Pedagogia. Assim, esta pesquisa desenvolveu-se a partir das seguintes questões: quais as concepções de ciência demonstradas por concluintes do curso de Licenciatura em Pedagogia? Como as concepções apresentadas podem estar relacionadas ao processo formativo das licenciandas? Nesse sentido, esse artigo tem por objetivos: investigar as concepções de ciências de um grupo de licenciandas do curso de Licenciatura em Pedagogia da Universidade Estadual do Sudoeste da Bahia; relacionar as concepções apresentadas com o processo formativo, buscando uma compreensão dos interventivos no processo de formação das ideias sobre ciência pelas licenciandas, e, por fim, levantar propostas de formação para a licenciatura investigada.

Estudos revelam que as concepções distorcidas dos professores sobre a ciência podem influenciar a prática pedagógica e, deste modo, comprometer os resultados da aprendizagem dos educandos, bem como concorrer para que adquiram visões distorcidas de ciência e tecnologia e de suas implicações na e para a sociedade (GARCÍA-RUIZ; OROZCO SÁNCHEZ, 2008; GUISASOLA; MORENTIN, 2007; HARRES, 1999; LACUEVA, 2010; LEDERMAN, 1992; PUJALTE et al., 2014; RODRIGUES; VIEIRA, 2012).

Reconhecemos que as concepções implícitas dos professores de Ciências são formadas por um longo processo que tem início na escolaridade básica e, muitas vezes, ultrapassa o período de formação no Ensino Superior, sendo sustentadas, inclusive, pela cultura extraescolar. Vários são os fatores que influem para a formação e perpetuação dessas concepções: (i) interferência dos professores ao longo da vida escolar; (ii) a maneira como a mídia apresenta a ciência e a tecnologia; (iii) visões distorcidas de ciência e tecnologia nos livros didáticos, dentre outros (CACHAPUZ et al., 2005; KOSMINSKI; GIORDAN, 2002). 
Embora não esteja livre de polêmicas, é possível apontar algumas características da natureza da ciência que devem ser abordadas em sala de aula. Assim os educandos devem: reconhecer que a ciência é permeada de tentativas e erros; é baseada em experiências empíricas; é subjetiva, posto que é influenciada pelos consensos entre os pesquisadores; é produto da imaginação humana, da criatividade e da atividade humana; é inerente à atividade social e cultural (GUISASOLA; MORENTIN, 2007).

A natureza da ciência, no entendimento de Guisasola e Morentin (2007, p. 247), engloba "aspectos de diferentes áreas como a História, a Sociologia e a Filosofia da ciência com o objetivo de explorar o que é a ciência, como trabalham os cientistas como grupo social e como a própria sociedade enfrenta e reage aos problemas derivados da ciência”. Portanto, julgamos pertinente que os professores em formação construam conhecimentos sobre a natureza da ciência, visto que necessitam conhecer as especificidades da área científica, entendendo que a ciência é produção histórica, humana e situada em determinado contexto político e socioeconômico.

As concepções de ciência sofrem influências das práticas sociais e das estruturas políticas em determinado contexto histórico e, por sua vez, influenciam a sociedade (HABERMAS, 2006). Podemos observar que, no transcurso da história, as concepções de ciência atuam como agentes ideológicos, pois operam fortuita interferência sobre outros campos da atividade humana: político, social, filosófico etc. De acordo com Habermas (2006), existem três grandes abordagens científicas: empírico-analitica, histórico-bermenêutica e crítica.

A abordagem empírico-analítica é marcada pelo caráter lógico-metodológico, fundamentada na regra, na experimentação e na observação controlada, com vistas à comprovação de hipóteses de forma objetiva. Nesta concepção, defende-se a neutralidade científica e prega-se que os fatos já estão postos, basta serem "descobertos" pelo pesquisador de forma objetiva. A construção do conhecimento parte da teoria para a prática. A primeira exerce posição de superioridade e baliza a segunda. Sendo assim, essa abordagem de ciência é guiada pelo interesse técnico do conhecimento, visando o controle da natureza e da sociedade (HABERMAS, 2006).

A abordagem histórico-hermenêutica fundamenta-se em um viés metodológico interpretativo, posto que valoriza os aspectos ligados à compreensão das coisas pertencentes à realidade, a qual é construída intersubjetivamente na produção do conhecimento. Nessa concepção, é atribuída grande importância ao papel do homem enquanto intérprete do mundo. Desse modo, os conhecimentos científicos são resultado das "leituras" que o pesquisador ou cientista faz dos fenômenos e dos fatos que envolvem seu entorno, ou seja, sua prática cotidiana. Refutando toda forma de objetividade, os produtos da ciência são o que os sentidos podem captar de forma subjetiva. Segundo Habermas (2006), essa abordagem é envolvida pelo interesse prático do conhecimento, visando, portanto, a compreensão da realidade.

A abordagem crítica, por seu turno, examina as produções teóricas da ciência e suas incidências ideológicas sobre a ação social, valendo-se da autorreflexão, pois "esta liberta o sujeito da dependência de poderes hipostasiados" (HABERMAS, 2006, p. 140). Os produtos

\footnotetext{
${ }^{3}$ Habermas refere-se aos poderes sobrepostos à sociedade, os quais exercem função alienante e opressora sobre as pessoas, expropriando-as de sua capacidade autorreflexiva e criadora. Tais poderes são exercidos por instituições sociais, sob a influência de determinadas concepções de ciência que separam a ação humana e a reflexão. O termo hipostasiados é uma derivação de hipóstese, palavra de origem grega que, segundo Ferreira (2001), significa "ficção tomada como real".
} 
da ciência são considerados como constructos humanos, situados em determinados contextos, influenciados por questões políticas, econômicas e culturais, por isso, não se aceita neutralidade na produção dos conhecimentos científicos. Desse modo, a ciência não é produtora de verdades irrefutáveis, mas de certezas provisórias, passíveis de reformulações, de crítica, de contestação e de substituição por novos conhecimentos. Ao contrário das anteriores, a ênfase na produção do conhecimento não está na teoria, nem na prática, mas busca a superação dessa dicotomia. Desse modo, a abordagem crítica de ciência, por meio da autorreflexão, é guiada pelo interesse emancipatório do conhecimento. Assim, por meio do exercício autorreflexivo, conhecimentos novos são produzidos com vistas à emancipação humana (HABERMAS, 2006).

\section{Percurso metodológico}

Esta pesquisa foi fundamentada na abordagem qualitativa, na qual, de acordo com Bogdan e Biklen (1997), as questões da pesquisa não se sustentam na construção de variáveis, pois têm a finalidade de investigação dos fenômenos em sua totalidade, complexidade e contexto natural. González Rey (2005), por sua vez, define a pesquisa qualitativa a partir de uma perspectiva epistemológica, definindo três características que a embasam.

i) a epistemologia qualitativa defende o caráter construtivo e interpretativo do conbecimento: o que implica reconhecer "o conhecimento como produção e não como apropriação linear de uma realidade que se nos apresenta” (GONZÁLEZ REY, 2005, p. 5). Nesse sentido, o conhecimento é concebido como produção humana, e não como algo pronto que se deva descobrir por meio de categorias universais.

ii) na epistemologia qualitativa, há a legitimação do singular como instância de produção do conhecimento científico, o que implica a valorização do conhecimento teórico produzido na pesquisa, visto que este resulta de um "processo construtivo-interpretativo" do pesquisador (GONZÁLEZ REY, 2005, p. 10).

iii) na epistemologia qualitativa, a pesquisa é compreendida como um processo de comunicação, um processo dialógico: a comunicação é de suma importância no desenvolvimento da pesquisa, pois permite "conhecer as configurações e os processos de sentido subjetivo que caracterizam os sujeitos individuais e que permitem conhecer o modo como as diversas condições objetivas da vida social afetam o homem” (GONZÁLEZ REY, 2005, p. 13).

Considerando as bases da abordagem qualitativa explicitadas por Bogdan e Biklen (1997) e suas implicações teóricas e epistemológicas postuladas por González Rey (2005), justificamos nossa opção pela mesma, pois permite analisar as concepções de ciência dos licenciandos, o que implica considerar os sentidos que estes atribuem às suas vivências durante o processo formativo.

O contexto da pesquisa foi o curso de Licenciatura em Pedagogia da Universidade Estadual do Sudoeste da Bahia, campus de Jequié, o qual foi implementado no ano de 1998, com o objetivo de formar profissionais para atuarem no ensino dos anos iniciais e educação infantil. Desde sua criação, o curso oferta oitenta vagas anuais, as quais são distribuídas entre os turnos matutino (quarenta vagas) e noturno (quarenta vagas). Além disso, vale ressaltar que esta licenciatura atrai discentes de vários municípios do sudoeste baiano.

Os sujeitos da pesquisa foram dez discentes do sexo feminino, escolhidas ao acaso, levando em consideração os seguintes critérios: ter cursado a disciplina Conteúdos e Metodologia 
do Ensino Fundamental de Ciências, estar regularmente matriculada no VIII período letivo (último semestre) do curso e aceitar participar da pesquisa. Além disso, contamos, também, com a participação da docente da disciplina Conteúdos e Metodologia do Ensino Fundamental de Ciências (CMEFC). Todas as participantes foram identificadas com nomes fictícios, a fim de preservar-lhes a identidade: Celi, Rosa, Juli, Nara, Lana, Nina, Tânia, Lícia, Mary, Suse. A docente foi codnominada de Vera.

Dentre as discentes, nove atuavam na Educação Básica entre dois meses a quatro anos, e uma não tinha experiência na área de educação. O tempo de experiência em ensino varia entre zero (Nara), dois a seis meses (Tânia e Lana), um a dois anos (Nina e Suse), dois a três anos (Celi, Juli e Lícia), quatro anos (Rosa e Mary). Vera, a docente da disciplina CMEFC é licenciada em Ciências Biológicas, especialista em Metodologia do Ensino Superior, com mestrado e doutorado em Educação. Atua no Ensino Superior há 22 anos, atuou durante três anos na Educação Básica e, atualmente, leciona nos cursos de licenciatura em Ciências Biológicas e em Pedagogia. O tempo em que leciona a disciplina é de três semestres acadêmicos.

Os dados da pesquisa foram coletados em duas fases: a primeira consistiu no levantamento e análise documental, na qual exploramos os seguintes documentos: Projeto Pedagógico do Curso (PPC); Fluxograma do curso e Ementa da disciplina CMEFC. Com base na técnica de análise documental ${ }^{4}$, buscamos informações referentes à concepção epistemológica do curso, ou seja, intentamos levantar as concepções de construção de conhecimento referendadas nesses documentos. Os documentos foram analisados separadamente, inicialmente com uma leitura geral e, posteriormente, foram realizadas outras leituras a fim de se destacarem as unidades de análise. Ao término desse processo, confrontamos os resultados obtidos em cada documento entre si e com os resultados das entrevistas.

$\mathrm{Na}$ segunda fase da pesquisa, realizamos entrevistas semiestruturadas com as dez discentes do VIII período acadêmico e com a docente da disciplina CMEFC. Após a transcrição e revisão das entrevistas, foram analisadas por meio da técnica de análise textual discursiva com base em Moraes e Galiazzi (2011). Para tal, primeiramente, fizemos a desmontagem dos textos das entrevistas (unitariz̧ação), ou seja, procuramos opiniões relativas à ciência; realizamos a categorização, que consistiu no estabelecimento de relações entre as opiniões sobre ciência e as categorias, em consonância com a análise dos documentos, e, por fim, elaboramos o texto de análise das categorias com base em fundamentos teóricos.

Devido à limitação de espaço, neste trabalho, apresentaremos trechos extraídos das entrevistas, buscando estabelecer, quando possível, relação com os resultados da análise dos documentos. Os procedimentos na íntegra poderão ser obtidos na dissertação de mestrado que originou esse artigo (SOUZA, 2013).

\footnotetext{
${ }^{4} \mathrm{~A}$ análise documental é uma técnica de pesquisa bastante pertinente para desvelar sentidos ocultos em fontes documentais. De acordo com Lüdke e André (1986, p. 38), “a análise documental consiste numa técnica valiosa de abordagem de dados qualitativos, seja complementando as informações obtidas por outras técnicas, seja desvelando aspectos novos de um tema ou problema".
} 


\section{Resultados e discussões}

Com o intuito de investigar a concepção de ciência das licenciandas entrevistadas, da docente da disciplina CMEFC, e nos documentos, procuramos por opiniões e fragmentos que caracterizam a ciência, tratem de sua relação com outros aspectos na sociedade e formas de produção do conhecimento. Com base na classificação empreendida por Habermas (2006), relacionamos os fragmentos encontrados a uma das concepções de ciência: empírico-analiticas, ou positivista, histórico-hermenêticas ou hermenêutica e críticas.

\section{Concepção positivista de ciência}

A mídia tem difundido alguns aspectos dessa concepção, quando divulga que ciência pressupõe comprovação de algo ou descobertas novas, sob a responsabilidade de cientistas em laboratórios (KOSMINSKI; GIORDAN, 2002). Não foram encontrados, nos documentos, indícios dessa concepção. No entanto, nos depoimentos de oito entre dez discentes, apareceram termos como: "comprovado", "descoberto", "descobertas", "novas descobertas", "verificação" e "estudo das coisas naturais", conforme exemplificado nos fragmentos abaixo, os quais explicitam que as mesmas entendem a ciência como capaz de comprovar, verificar, testar questões investigadas e que produza novas descobertas.

Acho que ciência [...] é o comprovado [...] é algo que foi comprovado, que um teórico estudou e comprovou e ali a gente entende por ciência [...] que é algo confirmado, não é algo do senso comum.... [Celi]

[...] ciência é tudo que pode ser analisado, tudo que pode ser comprovado [...] ciência é o estudo que pode ser comprovado, tudo que você pode é... dar uma certeza, é investigação, algo... você pegar um objeto, investigar aquele objeto, que seja o seu objeto de estudo, e a partir dali você chegar a uma conclusão.... [Mary]

[...] a própria mídia [...] coloca a ciência como algo que foi descoberto, eu acho que pra mim é colocada assim, como a descoberta nova que surgiu [...] a ciência está ligada a isso: sempre a uma nova descoberta ou algo novo que surgiu.... [Lana]

No depoimento de Lana, é possível perceber, expressamente, a influência da mídia na construção de sua concepção de ciência. Cachapuz et al. (2005, p. 46) afirmam que a concepção positivista de ciência difunde uma imagem ingênua de ciência, "socialmente difundida e aceita", atribuindo "a essência da atividade científica à experimentação", caracterizando a ciência como "descobrimento científico", como é divulgado pelos meios de comunicação.

É possível observar nos depoimentos abaixo, que Rosa e Lícia veem a ciência como o "estudo dos seres vivos", "das coisas naturais", especificamente do ser humano, plantas e animais.

[ciência] é o estudo da vida [...] é o conbecimento da vida [...] É... o conbecimento dos seres [...]. Tudo o que existe em nosso mundo. [Rosa] 
[...] seria o estudo [...] das coisas naturais [...] eu penso assim. [...] eu penso que é [...] tudo assim, que são as coisas naturais [...] do ser bumano, do corpo bumano, [...] de vege... de animais, essas coisas assim, mas o conceito [...] seria o estudo de tudo que vem a ser natural, envolvendo o ser humano, animais, plantas... [Lícia]

As ideias das discentes manifestam visões naturalistas de ciência, pois, ao perceberem-na por esse prisma, excluem-se as questões socioculturais que estão envolvidas nessa área. Nessa perspectiva, os fatores existentes na sociedade não são objeto de apreciação científica, pois a mesma se ocupa da investigação das coisas naturais. De acordo com Habermas (2006), a concepção positivista ou empírico-analítica de ciência, além de atribuir grande valor aos métodos experimentais, procede na descrição dos fatos e fenômenos naturais. Os conhecimentos e produtos da ciência são prognósticos, em virtude da sua validade técnica e rigorosidade metódica na construção e aplicação das teorias à realidade.

Visto que essa foi a concepção mais presente nas entrevistas realizadas, e como essas discentes estão em fase de conclusão do curso, entendemos que elas poderão reforçar essa concepção em sala de aula, influenciando a aprendizagem das crianças ou contribuindo para que reconheçam a ciência enquanto produtora de verdades acabadas, de forma acrítica e a-histórica.

\section{Concepção hermenêutica de ciência}

Nos documentos referentes ao curso em questão, não encontramos fragmentos relativos a essa concepção. No entanto, identificamos princípios da concepção hermenêutica nas entrevistas de duas entre dez discentes, quando mencionaram aspectos como: "estudo de algo" ou pesquisa de um tema sem, necessariamente, pautar-se em aportes científicos, ciência enquanto estudo para se chegar a uma teoria, busca de conhecimento por impulsos individuais. Nas opiniões abaixo, ciência é uma atividade de busca pelo conhecimento por meio de pesquisas e estudos.

Eu definiria ciência como conhecimento. Não sópautado na base de um conbecimento científico [...] e que ciência hoje ela foge, eu penso, daquela concepção que se tinha antes: pensava em ciência e já vinha logo um cientista com aqueles cabelos tudo voando, com aquela concepção [...]. Hoje eu acho que o que você se propõe a estudar [...] a conhecer sobre algo, a buscar conhecer, en acho que aquilo ali é ciência, eu penso. [Nara]

O cientista não necessariamente está inserido naquele laboratório, mas o cientista ele pesquisa, ele é... imbuído por uma curiosidade, então, só pelo fato desse [...] desejo de buscar, de tá esclarecendo, eu acho que [...] pode se considerar que ele é um cientista. [Tânia]

A concepção hermenêutica, segundo Habermas (2006), atribui à ciência o papel de produção do conhecimento por meio da interpretação subjetiva, partindo da prática à teoria. Nesta, "em vez da observação, é a compreensão de sentido que abre o acesso aos fatos" (HABERMAS, 2006, p. 138). Apesar de evidenciarem elementos da concepção hermenêutica de ciência, as discentes Nara e Tânia demonstram que há discussões sobre o que é ciência no curso em questão; 
isso é perceptível quando elas mencionam que não consideram os cientistas como seres à parte do mundo, isolados em laboratórios, vestidos de jalecos brancos, mas pessoas que produzem conhecimentos com base em pesquisas, inclusive, os diversos pesquisadores da academia.

Observamos, na fala de Nara, certo conflito de opinião, pois, ao mesmo tempo em que afirma que ciência é conhecimento, complementa que esse não deva ser, necessariamente, científico. Está evidenciado no depoimento da discente que ciência é vista como uma atividade pouco metódica, posto que o conhecimento pode ser produzido pela busca e estudo de algum tema ou assunto.

Com isso, observamos que Nara e Tânia expressam tentativas de superação de visões simplistas de ciência e, por isso, nos levam a perceber que estão em processo de reconstrução ou mudança de suas concepções de ciência, o que pode ter relação com as discussões da disciplina CMEFC, pois a professora formadora nos informou, em sua entrevista, que trabalhou um tópico em sala de aula em que se problematizou o que é ciência.

Anuímos que a formação das concepções de ciência das discentes tem início em períodos anteriores ao Ensino Superior; no entanto, defendemos que esta etapa formativa seja propícia para novas formulações, que, às vezes, não são possíveis por interventores, como por exemplo, estruturação das disciplinas de formação específica na licenciatura, sobretudo no que diz respeito à carga horária, como podemos perceber no depoimento da docente da disciplina CMEFC.

[...] O grande limite da disciplina, que eu acho é a questão do tempo, que são 60 boras, não é que 60 horas seja pouco [...] é uma quantidade suficiente pra se trabalhar muitas questões, mas considerando que [...] o curso de Pedagogia não tem outra disciplina de Ciências, então essa disciplina, ela não dá conta de todos os conteúdos de Ciências [...] que são trabalhados [...] nas séries iniciais do Ensino Fundamental. [Vera]

A formação de professores generalistas para os anos iniciais tem se constituído um grande desafio, especialmente no que tange à preparação para as disciplinas específicas. O depoimento da docente nos leva a afirmar que a carga horária da disciplina CMEFC determinou o não-aprofundamento de algumas questões fundamentais na formação do pedagogo, levando a formadora a ter de lançar mão de uma abordagem incipiente de alguns temas em detrimento de outros, para o cumprimento da ementa.

\section{Concepção crítica de ciência}

Não encontramos nenhuma opinião nos depoimentos das discentes que nos dessem base para relacionar a esta concepção. Na entrevista à docente da disciplina CMEFC, encontramos um fragmento relativo à concepção crítica de ciência, pois ela afirma que a ciência tem o papel de promover o desenvolvimento da reflexão crítica das pessoas, a fim de que estas tenham possibilidades de agir e transformar a sociedade em que vivem.

[...] ciência é [...] todo conhecimento produzido, e é claro que enquanto conbecimento, ele tem um papel fundamental na sociedade, no sentido de fazer as pessoas pensarem, 


\begin{abstract}
refletirem, porque na verdade, o que se espera do conhecimento, [...] da ciência, da tecnologia, [...] são as mudanças na sociedade, que esse conbecimento possa ajudar, possa contribuir [...] na vida das pessoas, de forma que elas possam refletir e transformar e agir de forma crítica e reflexiva na sociedade. [Vera]
\end{abstract}

Evidenciam-se, na fala, elementos críticos como: "mudanças sociais", "reflexão", "transformação" e "ação crítica e reflexiva", dos quais a ciência deveria incumbir-se. Na ementa da disciplina CMEFC, encontramos os seguintes indícios de conotação crítica nos tópicos: "educação e sociedade" e "movimento CTS", além da "natureza da ciência", o que indica proposta de estudos sobre filosofia e história da ciência, a fim de que esta seja encarada de forma crítica e influenciada por fatores políticos, sociais e culturais. Também consta, no objetivo geral, que a disciplina pretende analisar o ensino de Ciências como forma de preparação para a cidadania, de maneira que os discentes possam compreender a ciência de forma ampla, percebendo seus limites e possibilidades de intervenção na sociedade por meio da "compreensão mais ampla dos significados da ciência, das suas limitações e do seu potencial de ação sobre a sociedade como um todo" (UNIVERSIDADE ESTADUAL DO SUDOESTE DA BAHIA, 2001, p. 1). Com base nesses elementos, constatamos que a concepção crítica de ciência embasa a ementa da disciplina CMEFC.

Embora não esteja explicitada a concepção de ciência no PPC do curso de Licenciatura em Pedagogia, extraímos alguns fragmentos que nos deram base para análise desta categoria no referido documento. No texto que trata sobre a concepção do curso, consta que este deverá fornecer uma formação generalista que capacite, ao profissional, "analisar, com, rigor a realidade educacional e social, seus problemas e necessidades, para posiciona-se frente a ela de forma compreensiva e crítica" (UNIVERSIDADE ESTADUAL DO SUDOESTE DA BAHIA, 1997, p. 9). Já no texto que justifica os objetivos do curso de Pedagogia, consta que os profissionais formados deverão "ser capazes de chegar a uma profunda compreensão da escola enquanto realidade concreta e inserida no contexto histórico-social (inclusive dos mecanismos de dominação aí atuantes)" (UNIVERSIDADE ESTADUAL DO SUDOESTE DA BAHIA, 1997, p. 10).

Identificamos que a concepção crítica de ciência permeia os fragmentos citados, pois o documento preconiza a análise profunda da realidade socioeducacional, não apenas para produção de conhecimento da mesma, mas para compreendê-la de forma crítica, com vistas à intervenção. No PPC, está posto que as disciplinas integradas à Prática da Pesquisa Educacional são responsáveis por fomentarem a análise profunda da educação inserida no contexto político e social para promover a compreensão dos discentes. Nesse sentido, o PPC revela intencionalidades de emancipação do profissional formado, o qual deverá atuar enquanto agente de crítica aos modelos estabelecidos e buscar meios para a criação de uma escola com ideias de formação para a cidadania participativa.

Ao cruzarmos os resultados da análise, consideramos que, nas entrevistas das discentes, prepondera a concepção empirico-analítica de ciência, com a existência de alguns indícios de orientação hermenêutica; por outro lado, a docente da disciplina CMEFC, bem como os documentos analisados, evidenciaram uma concepção mais crítica de ciência.

Apresentamos, abaixo, o quadro sintético com as concepções de ciência identificadas nos dados da pesquisa, as quais foram manifestadas pelas discentes, docente da disciplina CMEFC, e levantadas nos documentos analisados. 
Quadro 1. Concepções de ciência levantadas nos dados.

\begin{tabular}{|c|l|l|l|l|}
\hline Concepções & \multicolumn{1}{|c|}{ Discentes } & \multicolumn{1}{|c|}{ Docente } & \multicolumn{1}{|c|}{ PPC } & \multicolumn{1}{|c|}{ Ementa } \\
\hline Positivista & $\begin{array}{l}\text { Ciência como } \\
\text { comprovação, } \\
\text { experimentação, novas } \\
\text { descobertas e estudo de } \\
\text { fenômenos da natureza. }\end{array}$ & Não houve & Não houve & Não houve \\
\hline Hermenêutica & $\begin{array}{l}\text { Pesquisa sobre algo, } \\
\text { conhecer algo por meio } \\
\text { da busca pessoal. }\end{array}$ & Não houve & Não houve & Não houve \\
\hline Não houve & $\begin{array}{l}\text { Ciência como } \\
\text { produção de } \\
\text { conhecimento e } \\
\text { mecanismo de } \\
\text { transformação } \\
\text { da consciência } \\
\text { humana e da } \\
\text { realidade. }\end{array}$ & $\begin{array}{l}\text { Cinvestigação } \\
\text { do objeto para } \\
\text { intervenção na } \\
\text { realidade. }\end{array}$ & $\begin{array}{l}\text { Ciência como } \\
\text { produção } \\
\text { histórica humana } \\
\text { e mecanismo de } \\
\text { transformação } \\
\text { da realidade e } \\
\text { formação do } \\
\text { pensamento crítico. }\end{array}$ \\
\hline
\end{tabular}

Fonte: Elaborado pelas autoras a partir de dados da pesquisa.

\section{Considerações finais}

Assim, com base na análise dos dados, podemos afirmar que é latente a necessidade de condições que possibilitem, às discentes, problematizarem suas concepções de ciência, visto que a formação do curso lhes concede a licença para atuar em um vasto campo educacional, inclusive, ensinando Ciências para as crianças. Além disso, percebemos que os tempos e espaços de formação da disciplina CMEFC não foram suficientes para promover a reconstrução de concepções simplistas de ciência e construção de concepções de cunho mais crítico.

A análise nos revelou as perspectivas constantes no PPC, na ementa da disciplina CMEFC e nas manifestações da docente, as quais não foram materializadas na construção ou revisão das concepções de ciência das discentes durante o curso estudado. Todavia, tal afirmação não significa que esses aspectos tenham sido negligenciados na disciplina de CMEFC e nas demais disciplinas do curso, pois, em algumas delas, aborda-se sobre a ciência e a natureza do trabalho científico, como por exemplo: filosofia, sociologia, antropologia e metodologia da pesquisa científica. O que pode explicar a predominância da concepção empirico-analítica nas discentes é a impregnação, durante toda a vida escolar, de uma única concepção de ciência, divulgada pelos livros didáticos, pela mídia e, até mesmo, pelos docentes, visto que as concepções destes influenciam a prática pedagógica do ensino de Ciências, bem como a formação das concepções 
pelos educandos (GUISASOLA; MORENTIN, 2007; RODRIGUES; VIEIRA, 2012). Por outro lado, parece claro que o curso não foi capaz de fazer com que essas licenciandas problematizassem suas concepções acerca da natureza da ciência.

As concepções de ciência evidenciadas nos depoimentos das discentes apontam para a necessidade de levantamento de estratégias que garantam, aos futuros professores do curso de Licenciatura em Pedagogia, uma visão mais esclarecida e mais crítica da ciência.

Nesse sentido, levantamos algumas propostas para a formação do pedagogo, sem a pretensão de apresentá-las como respostas únicas ou soluções infalíveis, mas que poderão colaborar para o desenvolvimento de professores dos anos iniciais mais preparados para ministrar aulas de Ciências.

Assim, defendemos que haja no referido curso:

i) maior ênfase nas discussões sobre a natureza da ciência no processo de formação, por meio do exercício da crítica e autorreflexão, de modo que tanto a ciência quanto os fundamentos (teorias) da educação sejam colocados no crivo das indagações por professores formadores e professores em formação. Carvalho e Gil-Pérez (2003) discutem as habilidades formativas dos professores de Ciências e asseveram a importância de discussões sobre a ciência, tecnologia e sua relação com o contexto social, o que favorece a superação de visões ingênuas da ciência.

ii) ampliação da carga horária da disciplina CMEFC, com o propósito de favorecer o aprofundamento dos conteúdos abordados e ampliação das estratégias formativas, a fim de que o licenciando tenha possibilidades de vivenciar/articular os conhecimentos teóricos com a prática, incluindo práticas nas escolas básicas desde os primeiros semestres do curso.

iii) problematização das situações concretas, ou seja, dos problemas que envolvem o ensino/aprendizagem, o que torna possível a adoção de novas práticas pedagógicas em sala de aula, inclusive no ensino de Ciências Naturais.

iv) formação com base na pesquisa, pois esta atividade tem sido considerada profícua no processo de formação de professores (CARVALHO; GIL PÉREZ, 2003).

Desse modo, a formação inicial para o ensino de Ciências poderá fornecer suporte que convirja a uma ação pedagógica capaz de dar oportunidade às crianças de aprenderem conteúdos científicos de forma dinâmica e indagadora.

Portanto, anuímos que, dentre outras questões, é mister a intensificação das discussões sobre a natureza da ciência no processo de formação do pedagogo, a fim de que a ciência não seja vista apenas como produto, e sim como processo, influenciada por aspectos históricos e socioculturais, e imbricada por interesses ideológicos.

\section{Referências}

ANDRADE, C. S. Concepções de alunos de pedagogia da UFRN acerca da natureza da ciência: subsídios à formação de professores. 2008. 181 f. Dissertação (Mestrado em Educação) - Universidade Federal do Rio Grande do Norte, Natal, UFRN, 2008.

BOGDAN, R. C.; BIKLEN, S. K. Investigação qualitativa em educação: uma introdução à teoria e aos métodos. Porto: Porto Editora, 1997. 
CACHAPUZ, A. et. al. A necessária renovação do ensino de ciências. São Paulo: Cortez, 2005.

CARVALHO; A. M. P.; GIL-PÉREZ, D. Formação de professores de ciências: tendências e inovações. São Paulo: Cortez, 2003.

FERREIRA, A. B. de H. Minidicionário da língua portuguesa. Rio de Janeiro: Nova Fronteira, 2001.

GARCÍA-RUIZ, M.; OROZCO SÁNCHEZ, L. Orientando un cambio de actitud hacia las ciencias naturales y su enseñanza en profesores de educación primaria. Revista Electrónica de Enseñanza de las Ciencias, Vigo, v. 7, n. 3, p. 539-568, 2008. Disponível em: < http:// reec.uvigo.es/volumenes/volumen7/ART3_Vol7_N3.pdf>. Acesso em: 26 ago. 2015.

GONZÁLEZ REY, F. Pesquisa qualitativa e subjetividade: os processos de construção da informação. São Paulo: Pioneira Thomson Learning, 2005.

GUISASOLA, J.; MORENTIN, M. Comprenden la natureza de la ciencia los futuros maestros y maestras de educación primaria? Revista Electrónica de Enseñanza de las Ciencias, Vigo, v. 6, n. 2, p. 246-262, 2007. Disponível em: <http://reec.uvigo.es/ volumenes/volumen6/ART2_Vol6_N2.pdf>. Acesso em: 26 ago. 2015.

HABERMAS, J. Conhecimento e interesse. In: Técnica e ciências como “ideologia”. Lisboa: Edições 70, 2006. p. 129-147.

HARRES, J. B. S. Uma revisão de pesquisas nas concepções de professores sobre a natureza da ciência e suas implicações para o ensino. Investigações em Ensino de Ciências, Porto Alegre, v. 4, n. 3, p. 197-211, 1999.

KOSMINSKI, L.; GIORDAN, M. Visões de ciências e sobre cientistas entre estudantes do ensino médio. Química Nova na Escola, São Paulo, n. 15, p. 11-18, maio 2002. Disponível em: <http://qnesc.sbq.org.br/online/qnesc15/v15a03.pdf>. Acesso em: 26 ago. 2015.

LACUEVA, A. Formando docentes integrales que quieren y puedan enseñar ciencia y tecnología. Revista Electrónica de Enseñanza de las Ciencias, Vigo, v. 9, n. 2, p. 309-332, 2010. Disponível em: <http://saber.ucv.ve/jspui/handle/123456789/2303>. Acesso em: 26 ago. 2015.

LEDERMAN, N. G. Students' and teachers' conceptions of the nature of science: a review of the research. Journal of Research in Science Teaching, Hoboken,v. 29, n. 4, p. 331-359, 1992.

LONGHINI, M. D. O conhecimento do conteúdo científico e a formação do professor das séries iniciais do ensino fundamental. Investigações em Ensino de Ciências, Porto Alegre, v. 13, n. 2, p. 241-253, 2008.

LÜDKE, M.; ANDRÉ, M. Pesquisa em educação: abordagens qualitativas. São Paulo: EPU, 1986.

MORAES, R.; GALIAZZI, M. C. Análise textual discursiva. Ijuí: Editora Unijuí, 2011. 
OVIGLI, D. F. B.; BERTUCCI, M. C. S. A formação para o ensino de ciências naturais nos currículos de pedagogia das instituições públicas de ensino superior paulistas. Ciências e Cognição, Rio de Janeiro, v. 14, n. 2, p. 194-209, 2009. Disponível em: <http:/ /www. cienciasecognicao.org/revista/index.php/cec/article/view/134/92>. Acesso em: 26 ago. 2015.

PUJALTE, A. P. et al. Las imágenes inadecuadas de ciencia y de científico como foco de la naturaleza de la ciencia: estado del arte y cuestiones pendientes. Ciência \& Educação, Bauru, v. 20, n. 3, p. 535-548, 2014. Disponível em: <http://dx.doi.org/10.1590/1516$73132014000300002>$. Acesso em: 26 ago. 2015.

RODRIGUES, M. J.; VIEIRA, R. M. Programa de formação de educadores de infância: seu contributo para a (re) construção de concepções ciência-tecnologia-sociedade. Revista Electrónica de Enseñanza de las Ciencias, Vigo, v. 11, n. 3, p. 501-520, 2012. Disponível em: <http://reec.uvigo.es/volumenes/volumen11/REEC_11_3_2_ex664.pdf $>$. Acesso em: 26 ago. 2015.

SCHWARTZMAN, S.; CHRISTOPHE, M. A educação em ciências no Brasil. Rio de Janeiro: Academia Brasileira de Ciências, 2009.

SOUZA, A. L. S. A formação do pedagogo na UESB, campus de Jequié, para o ensino de ciências nos anos iniciais. 2013. 194 f. Dissertação (Mestrado em Educação Científica e Formação de Professores) - Universidade Estadual do Sudoeste da Bahia, Jequié, 2013.

UNIVERSIDADE ESTADUAL DO SUDOESTE DA BAHIA. Ementa da disciplina conteúdo e metodologia do ensino fundamental de ciências. Jequié: UESB, 2001.

Projeto de criação do curso de pedagogia. Jequié: UESB, 1997.

WEISSMANN, H. (Org). Didática das ciências naturais: contribuições e reflexões. Porto Alegre: Artmed, 1998. 